\title{
ANALISIS MOTIVASI TERHADAP ETOS KERJA ISLAMI PADA KARYAWAN UNIVERSITAS MUHAMMADIYAH RIAU
}

\author{
Rika Septianingsih ${ }^{1}$, Mohd. Ario Wahdi Elsye ${ }^{2}$ \& Putri Nuraini ${ }^{3}$ \\ ${ }^{1,2}$ Fakultas Studi Islam, Universitas Muhammadiyah Riau \\ ${ }^{3}$ Fakultas Agama Islam, Universitas Islam Riau \\ Email: rikaseptianingsih@umri.ac.id,ariowahdi@umri.ac.id,putrinuraini@fis.uir.ac.id
}

\begin{abstract}
ABSTRAK
Universitas Muhammadiyah Riau merupakan Universitas Swasta yang cukup pesat perkembangannya di Provinsi Riau. Keberadaannya saat ini sangat di perhitungkan di jajaran Universitas Swasta yang ada di Provinsi Riau. Universitas Muhammadiyah Riau yang berlandaskan Al Islam dan Kemuhammadiyahan selalu memberikan dorongan motivasi kepada seluruh pegawai yang ada untuk mencapai etos kerja yang nantinya akan berimbas pada kualitas pekerjaan dan tanggung jawab yang tinggi sebagaimana dalam Al-Qur'an telah menjelaskan bahwa konsep agama menekankan pada umatnya untuk bekerja dengan semangat etos kerja Islami. Dari penelitian yang telah dijalani diperoleh hasil bahwa Motivasi berpengaruh signifikan terhadap Etos Kerja Islami yang ada di Universitas Muhammadiyah Riau hal ini dibuktikan dengan beberapa motivasi yang telah dijalankan dapat menghasilkan karyawan yang memiliki etos kerja terukur berdasarkan nilai keislaman diantaranya, kejujuran, tanggung jawab, disiplin, gigih serta mengharap ridho Allah SWT atas pekerjaan yang dilakukan, yang mana pekerjaan bukan hanya sebagai tempat menghasilkan uang tetapi juga sarana beribadah..
\end{abstract}

Kata kunci : Motivasi, Etos Kerja Islami, Muhammadiyah.

\begin{abstract}
Muhammadiyah Riau University is a private university with a fairly rapid development in riau Province. Its current existence is very much teken into account in the rank of private universities in Riau Province. Muhammadiyah Riau University which is based on al Islam an kemuhammadiyahan always provides a motivational boost to all existing employees to achieve a work ethic which will later impact on the quality of work and high responsibility. As In the Al-Qur'an, it has been explained that the consept of religion emphasizes its people.to work in the spirit of an Islamic work ethic. From the research that has been undertaken, it is found that motivation has a significant effect on the Islamic Work Ethic at the University of Muhammadiyah Riau, this is evidenced by several motivations that have been carried out to produce employees who have a measurable work ethic based on Islamic values including honesty, responsibility, discipline, be persistent and expect Allah's approval for the work done, where work is not only a place to make money but also a means of worship.
\end{abstract}

Keywords : Motivation, Islamic Work Ethic, Muhammadiyah. 


\section{PENDAHULUAN}

Al-Qur'an menegaskan bahwa dan menjelaskan bahwa konsep agama menekankan pada umatnya untuk bekerja dan tidak melupakan kehidupan dunia dengan memiliki semangat etos kerja yang memiliki nilai-nilai keislaman (etos kerja islami). Firman Allah SWT dalam QS. AlQashas ayat 77 yang berbunyi:

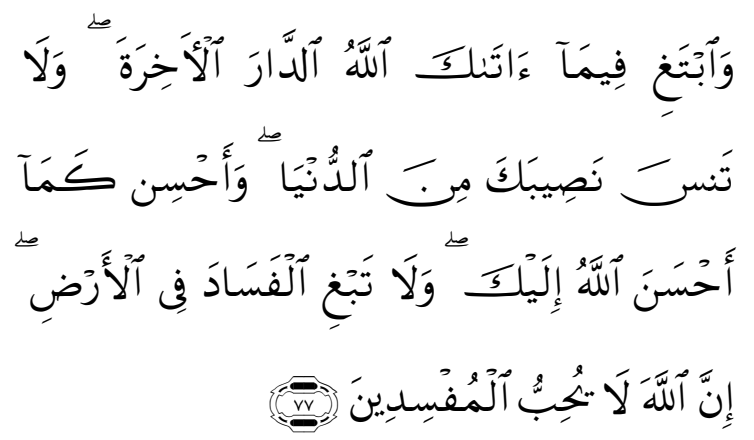

Artinya: "Dan carilah pada apa yang telah dianugerahkan Allah kepadamu (kebahagiaan) negeri akhirat, dan janganlah kamu melupakan bahagianmu dari (kenikmatan) duniawi dan berbuat baiklah (kepada orang lain) sebagaimana Allah telah berbuat baik, kepadamu, dan janganlah kamu berbuat kerusakan di (muka) bumi. Sesungguhnya Allah tidak menyukai orang-orang yang berbuat kerusakan".

Dalam upaya untuk mencapai peningkatan etos kerja Islami dikalangan para karyawan Universitas Muhammadiyah Riau dapat kita wujudkan dengan pendekatan psikologis, budaya dan agama. Kualitas seorang karyawan tergantung dengan etos kerja yang dimilikinya apakah landasan yang mereka pakai dalam menjalankan tugasnya sudah tepat atau belum. Para Karyawan yang memiliki etos kerja Islami yang tinggi biasanya memiliki sikap mental yang yang tinggi dalam menjalankan pekerjaan dan dapat tercermin pada prilaku disiplin, jujur, amanah serta bekerja keras tentu dapat kita bedakan pada prilaku karyawan yang tidak memiliki etos kerja Islami. Dengan segala kelebihan yang dimiliki oleh para karyawan Universitas Muhammadiyah Riau dalam perannya sebagai pengelola administrasi serta melayani baik itu steak holder, masyarakat, dosen, mahasiswa maupun pimpinan. penulis menilai upaya untuk pencapaian etos kerja yang Islami yang memicu etos kerja dilingkungan Universitas Muhammadiyah Riau masih belum maksimal sebagai contoh dari data wawancara awal dengan beberapa dosen mereka mengatakan masih banyak kesulitan dalam memperoleh arsip arsip serta ada beberapa pegawai yang sulit dijumpai untuk berkoordinasi karena masih ada beberapa pegawai yang keluar kantor disaat jam dinas serta masih adanya pegawai yang menolak untuk melaksanakan pekerjaan yang bukan tupoksi sehingga muncul rasa tidak ikhlas dalam bekerja.

Dalam penerapannya etos kerja Islami tidak terlepas dari peran kepemimpinan yang sangat dibutuhkan dalam memicu semangat dengan cara bimbingan dan arahan melalui pencerahan dibidang agama seperti kajian rutin serta ceramah-ceramah agama dalam hal ini pemimpin dapat mengingatkan selalu konsep dasar keislaman baik dalam ibadah maupun dalam aqidah akhlak. Dari hal tersebut pemimpin dapat mengevaluasi pegawai sebagai upaya motivasi dalam melakukan pekerjaan yang lebih baik. Pemimpin juga dapat mengontrol perilaku pegawai agar etos kerja semakin meningkat dan mencapai hasil yang telah ditetapkan oleh organisasi. Etos kerja seorang muslim, dibentuk oleh iman yang menjadi pandangan hidupnya, yang memberi norma-norma dasar untuk membangun dan membina muamalahnya. Seorang muslim dituntut oleh imannya untuk menjadi orang yang bertaqwa dan bermoral amanah, berilmu, cakap, cerdas, cermat, hemat, rajin, tekun dan bertekad bekerja sebaik mungkin untuk menghasilakn yang terbaik. Apabila 
seorang karyawan memiliki hal itu semua maka kinerjanya baik pula. Etos kerja dalam Islam adalah hasil suatu kepercayaan seorang muslim, bahwa kerja mempunyai kaitan dengan tujuan hidupnya, yaitu memperoleh perkenaan Allah SWT. Bagi orang yang beretos kerja Islami, etos kerjanya terpancar dari sistem keimanan atau aqidah Islami berkenaan dengan kerja yang bertolak dari ajaran wahyu bekerjasama dengan akal. Sistem keamanan itu, identik dengan sikap hidup mendasar (aqidah kerja).

\section{TINJAUAN PUSTAKA}

Motivasi merupakan salah satu hal yang sangat penting diperhatikan dalam perusahaan, karena hal ini sangat mempengaruhi prestasi kerja para karyawan yang ada di lingkungan perusahaan tersebut. Untuk memperjelas pengertian motivasi dapat dikemukakan beberapa pendapat para ahli tentang pengertian motivasi sebagai berikut:

1. Menurut Hasibuan dalam Sunyoto (2013) motivasi adalah suatu perangsang keinginan daya gerak kemauan bekerja seseorang, setiap motif mempunyai tujuan tertentu yang ingin dicapai.

2. Menurut Sedarmayanti (2009) Motivasi adalah suatu daya pendorong (driving force) yang menyebabkan orang berbuat sesuatu atau yang diperbuat karena takut akan sesuatu.

3. Menurut Siagian (2004) menyatakan bahwa yang diinginkan seseorang dari pekerjaannya pada umumnya adalah sesuatu yang mempunyai arti penting bagi dirinya sendiri dan bagi instansi Menurut Heidjachman dan Husnan motivasi merupakan proses untuk mencoba mempengaruhi seseorang agar melakukan sesuatu yang kita inginkan.

4. Menurut Wibowo (2011) motivasi berasal dari kata motif yang merupakan suatu dorongan atau keinginan karyawan mengerjakan pekerjaannya sesuai tanggung jawab agar tujuan perusahaan dapat tercapai

5. Menurut Samsudin (2010) motivasi adalah proses mempengaruhi atau mendorong dari luar terhadap seseorang atau sekelompok kerja agar mereka mau melaksanakan sesuatu yang ditetapkan

6. Menurut Schiffman dan Kanuk (2008) Motivasi adalah sebagai tenaga pendorong dalam individu yang memaksa mereka untuk bertindak.

7. Menurut Hasibuan (2002) motivasi berasal dari kata latin movere yang berarti dorongan atau daya penggerak. Motivasi ini hanya diberikan kepada manusia, khususnya kepada para bawahan atau pengikut.

Berdasarkan pendapat para ahli diatas, maka dapat disimpulkan bahwa motivasi merupakan dorongan yang dapat membangkitkan kemauan kerja karyawan untuk memulai melaksanakan pekerjaan sesuai tugas dan tanggung jawabnya. Motivasi juga merupakan suatu dorongan atau penggerak sehingga seseorang melakukan tindakan-tindakan yang memberikan sumbangan yang maksimal terhadap pencapaian tujuan yang diinginkan. Atau dengan kata lain motivasi merupakan faktor yang mendorong untuk bertindak dengan cara tertentu.

\section{Motivasi Kerja}

Hamzah (2008) menyatakan motivasi kerja adalah dorongan dari dalam diri dan luar diri seseorang untuk melakukan sesuatu yang terlihat dari dimensi internal dan dimensi eksternal. Motivasi Internal yaitu motivasi kerja yang bersumber dari dalam diri karyawan yang menimbulkan dorongan atau semangat untuk bekerja keras, dapat berupa kesadaran mengenai pentingnya 
makna pekerjaan yang dilaksanakan. Indikator motivasi internal meliputi:

1. Tanggungjawab karyawan;

2. Melaksanakan tugas;

3. Mempunyai tujuan yang jelas;

4. Umpan balik pekerjaan;

5. Perasaan senang bekerja;

6. Selalu berusaha untuk mengungguli orang lain;

7. Mengutamakan prestasi.

Motivasi eksternal yaitu motivasi yang bersumber dari luar diri individu karyawan, berupa kondisi yang mengharuskan melaksanakan pekerjaan secara maksimal. Indikator motivasi eksternal meliputi: (1) Berusaha untuk memenuhi kebutuhan hidup dan kebutuhan kerja; (2) Senang memperoleh pujian dari apa yang dikerjakannya; (3) Bekerja untuk ingin memperoleh insentif; (4) Bekerja dengan harapan ingin memperoleh perhatian dari atasan dan teman.

Lubis, Hermanto \& Edison (2018) menyatakan bahwa dalam perusahaan atau organisasi, setiap orang dituntut untuk melaksanakan pekerjaannya dengan motivasi kerja yang optimal. Sebab motivasi kerja merupakan energi pendorong yang membuat seseorang dapat bekerja maksimal. Makin tinggi motivasi kerja seseorang kian tinggi pula usaha yang ia lakukan dalam meningkatkan kinerja.

\section{Etos Kerja}

Etos kerja merupakan nilai-nilai yang membentuk kepribadian seseorang dalam bekerja. Etos kerja pada hakekatnya di bentuk dan dipengaruhi oleh sistem nilai yang dianut seseorang dalam bekerja. Yang kemudian membentuk semangat yang membedakannya antara yang satudengan yang lain. Etos kerja Islam dengan demikian merupakan refleksi pribadi seorang khalifah yang bekerja dengan bertumpu pada kemampuan konseptual yang dimilikinya yang bersifat kreatif dan inovatif. Menurut Sunyoto (2013) tujuan motivasi antara lain:

1. Mendorong gairah dan semangat kerja karyawan;

2. Meningkatkan moral dan kepuasan kerja karyawan;

3. Meningkatkan produktivitas kerja karyawan;

4. Mempertahankan loyalitas dan kestabilan karyawan perusahaan;

5. Menciptakan suasana dan hubungan kerja yang baik;

6. Meningkatkan kreativitas dan partisipasi karyawan.

Menurut Rivai dalam Usman (2015) bangunan manajemen Islami didasarkan pada fondasi utama yaitu Tauhid. Tauhid menjadi dasar seluruh konsep dan aktifitas umat Islam, baik di bidang ekonomi dan manajemen, politik, sosial dan budaya. Fondasi berikutnya yaitu syariah dan akhlak. Dasar syariah membimbing aktifitas ekonomi dan manajemen sehingga sesuai dengan kaidah kaidah syariah. Sedangkan akhlak membimbing aktifitas ekonomi dan manajemen agar senantiasa mengedepankan moralitas dan etika untuk mencapai tujuan organisasi.

Etos kerja seorang muslim, dibentuk oleh iman yang menjadi pandangan hidupnya, yang memberi norma-norma dasar untuk membangun dan membina muamalahnya. Seorang muslim dituntut oleh imannya untuk menjadi orang yang bertaqwa dan bermoral amanah, berilmu, cakap, cerdas, cermat, hemat, rajin, tekun dan bertekad bekerja sebaik mungkin untuk menghasilkan yang terbaik. Apabila seorang karyawan memiliki hal itu semua 
maka kinerjanya baik pula. Etos kerja dalam Islam adalah hasil suatu kepercayaan seorang muslim, bahwa kerja mempunyai kaitan dengan tujuan hidupnya, yaitu memperoleh perkenaan Allah SWT. Bagi orang yang beretos kerja Islami, etos kerjanya terpancar dari sistem keimanan atau aqidah Islami berkenaan dengan kerja yang bertolak dari ajaran wahyu bekerjasama dengan akal. Sistem keamanan itu, identik dengan sikap hidup mendasar (aqidah kerja).

Nilai-nilai karakteristik etos kerja seseorang dapat dilihat dari:

1. Spiritual, yang berupa niat untuk beribadah kepada Allah SWT dan kerja keras/kesungguhan dalm bekerja;

2. Ilmu Pengetahuan, yaitu pengetahuan di bidang pekerjaannya;

3. Profesionalitas, atau menekuni keahliannya dalam bekerja.

Penelitian oleh Musriha (2011) dengan judul Influences of Work Behavior, Work Environment and Motivation in Clove Cigarette factories in Kudus, Indonesia. Hasil penelitiannya menunjukkan:

1. Lingkungan kerja secara signifikan berpengaruh terhadap kinerja karyawan di Pabrik rokok Kabupaten Kudus, Jawa Tengah.

2. Motivasi Kerja secara signifikan mempengaruhi kinerja pekerjaan pelinting rokok di Kabupaten Kudus, Jawa Tengah.

Penelitian oleh Bhargava R. Kotur, \& S. Anbazhagan (2014) dengan judul Education and WorkExperienceInfluenceon the Performance. Penelitian ini meneliti tingkat kinerja para pekerja di pabrik Chittoor Sugar terletak di Kota Chittoor dari India Selatan. Penelitian ini juga mempelajari bagaimana pendidikan faktor dan pengalaman kerja mempengaruhi tingkat kinerja para pekerja di perusahaan. Hasil penelitian menunjukkan bahwa dua variabel yaitu pendidikan dan pengalaman kerja memiliki pengaruh pada kinerja para pekerja.

\section{Motivasi}

Menurut Schiffman dan Kanuk (2008) motivasi digambarkan sebagai dorongan dari dalam diri individu seseorang dan memaksa dia untuk berbuat. Dorongan ini dihasilkan oleh tekanan yang timbul akibat dari satu kebutuhan yang tidak terpenuhi. Nitisusastro (2012) menambahkan ternyata terdapat korelasi antara motivasi dan kebutuhan. Jadi dapat disimpulkan bahwa motivasi menimbulkan dorongan agar kebutuhan seseorang terpenuhi.

Indikator variabel motivasi dalam penelitian ini merujuk pada Maslow (dalam Suprapti, 2010) yaitu: Kebutuhan Fisiologis, Kebutuhan Rasa Aman, Kebutuhan Sosial, Kebutuhan Ego, dan Kebutuhan Aktualisasi Diri.

\section{METODE PENELITIAN}

Penelitian ini bertempat di Universitas Muhammadiyah Riau. Adapun populasi dalam penelitian ini adalah karyawan Universitas Muhammadiyah Riau tahun 2020 berjumlah 98 orang. Pemilihan sampel dengan menggunakan purposive sampling yang mana peneliti menentukan sendiri kreteria sample yang akan dijadikan responden dalam penelitian ini. Menurut Sugiyono (2016) purposive sampling adalah teknik pengambilan sumber data dengan pertimbangan tertentu. Alasan menggunakan teknik puposive sampling adalah karena tidak semua sampel memiliki kriteria yang sesuai dengan fenomena yang diteliti. Oleh karena itu, penulis memilih teknik puposive sampling yang menetapkan pertimbanganpertimbangan atau kriteria-kriteria tertentu yang harus dipenuhi oleh sampel sampel yang digunakan dalam penelitian ini. 
Adapun kreteria yang diajukan berikut: untuk mendapatkan responden sebagai

\section{Tabel 1. Kriteria Sampling}

\begin{tabular}{clc}
\hline No. & \multicolumn{1}{c}{ Kriteria Sampling } & Jumlah \\
\hline 1 & Karyawan yang telah bekerja di UMRI di atas 10 tahun & 8 \\
\hline 2 & $\begin{array}{l}\text { Karyawan yang telah bekerja di UMRI di atas 5 tahun dan telah mengikuti Baitul } \\
\text { Arqam Al-Islam dan Kemuhammadiyah tingkat lanjut }\end{array}$ & 12 \\
\hline 3 & $\begin{array}{l}\text { Karyawan yang telah bekerja di UMRI di atas 5 tahun dan saat ini memiliki jabatan } \\
\text { ditingkat universitas }\end{array}$ & 10 \\
\hline
\end{tabular}

Dengan demikian responden yang dipakai dalam penelitian ini berjumlah 30 orang.

\section{Teknik Pengumpulan Data}

Tahapan tahapan analisis data yang penulis gunakan terdiri dari:

1. Penyebaran kuesioner yaitu memberikan kuesioner kepada responden yang terkait untuk mengisi dan menjawab dari kuesioner tersebut.

2. Mengklasifikasian kuesioner antara kuesinoer variabel independen dan dependen yang telah terkumpul sesuai dengan masalah yang telah ditetapkan.

3. Mengambil kesimpulan dari data yang telah diperoleh dari responden.

\section{Variabel Penelitian}

Variabel dalam penelitian ini terdiri atas variabel independen yaitu Motivasi, dan variabel dependen yaitu Etos Kerja Islami.

\section{Metode Analisis Data}

Untuk mengubah data kualitatif menjadi data kuantitatif maka digunakan skala pengukuran berupa skala likert. Analisa data dengan menggunakan SPSS 20.0 untuk menggambarkan hubungan motivasi terhadap etos kerja Islami. Teknik analisis yang digunakan adalah uji normalitas. Pengujian normalitas data dilakukan dengan menggunakan One Sample Kormogorov Smirnov Test, dengan melihat tingkat signifikansi 5\%. Dasar pengambilan keputusan dari uji normalitas adalah dengan melihat probabilitas asymp.sig (2- tailed) > 0,05 maka data mempunyai distribusi normal dan sebaliknya jika probabilitas asymp.sig (2- tailed $)>0,05$ maka data mempunyai distribusi yang tidak normal.

\section{Pengujian Hipotesis}

Pengujian hipotesis adalah prosedur yang akan menghasilkan keputusan, yaitu keputusan menerima atau menolak hipotesis tersebut. Untuk menguji hipotesis tersebut, maka data yang diperoleh dianalisis dengan uji T. Uji $\mathrm{T}$ (Uji Parsial), yaitu untuk menguji apakah variabel independennya secara parsial berpengaruh terhadap variabel dependen.

Terima Ho jika $\mathrm{T}$ hitung $<\mathrm{T}$ tabel $(\alpha=$ $0,05)$

Terima Ha jika $\mathrm{T}$ hitung $>\mathrm{T}$ tabel $(\alpha=$ $0,05)$

\section{HASIL DAN PEMBAHASAN}

Universitas Muhammadiyah Riau selalu menjunjung tinggi semangat Technopreneurship yang digalakkan disetiap kesempatan kepada seluruh jajaran staff juga mahasiswa/i. Kalimat technopreneur sendiri merupakan gabungan dari kata Technology dan Entrepreneur yang bisa dijabarkan sebagai berikut: Techno - Merupakan bukti bahwa Universitas Muhammadiyah Riau selalu mengikuti perkembangan zaman dari segala aspek. Semangat ini diaplikasikan tidak hanya di bidang kualitas pendidikan, namun juga turut dilaksanakan di bidang manajemen dan pengembangan sekaligus menurunkan semangat ini kepada setiap siswa/i. Universitas Muhammadiyah Riau kini merupakan salah satu universitas swasta 
di Pekanbaru yang lebih dulu menggunakan teknologi dalam proses ajar mengajar di kelas, publikasi dan dokumentasi, hingga manajemen data siswa dan universitas. Semua ini menunjukkan bahwa Universitas Muhammadiyah Riau sanggup untuk menjadi universitas yang berkualitas, bermutu, dan mengikuti perkembangan zaman, juga selalu berinovasi dalam memajukan pendidikan masyarakat Indonesia khususnya Pekanbaru Riau; Preneur - Ini adalah semangat yang membedakan Universitas Muhammadiyah dengan universitas dan perguruan tinggi lain yang ada di Pekanbaru.

Universitas Muhammadiyah Riau selalu percaya, bahwa siswa/i kami bukan dididik hanya untuk menjadi yang terbaik di bidang akademis, tapi juga menjadi yang terdepan dibidang Entrepreneur. Lulusan UMRI dituntut untuk selalu kreatif dan inovatif dalam dunia bisnis selepas mengenyam pendidikan di fakultas dan jurusan yang mereka minati. Tidak hanya nantinya setelah lulus para alumni akan menjadi orang yang berilmu, berakhlak, dan berkualitas untuk bersaing di dunia kerja, mereka juga akan memiliki semangat, wawasan, dan perencanaan yang matang untuk bersaing di dunia bisnis sebagai seorang Entrepreneur. Diharapkan nantinya para alumni kebanggan UMRI akan mampu menggerakkan roda perekonomian masyarakat Pekanbaru khusunya, dan bahkan membantu perekonomian secara nasional. Universitas Muhammadiyah Riau selalu berusaha memberikan yang terbaik bagi siswa/i bahkan alumni lulusannya, dengan harapan bahwa kualitas ini akan diturunkan ke generasi dan angkatan berikutnya hingga mampu mengembangkan pendidikan di Indonesia sekaligus ke Muhammadiyahan secara global. Amin ya rabbal alamin.

\section{Hasil Penelitian}

\section{Karakteristik Responden}

Berikut adalah rekapitulasi data identitas responden :

Tabel 2. Rekapitulasi Data Identitas Responden

\begin{tabular}{ccccc}
\hline No & & Indikator & Orang & Persentase (\%) \\
\hline 1 & Jenis Kelamin & & 11 & \\
& Laki-laki & & 19 & 36.67 \\
& Perempuan & Jumlah & $\mathbf{3 0}$ & 63.33 \\
2 & & & $\mathbf{1 0 0}$ \\
& Usia (Th) & & 8 & 26.67 \\
& $20-30$ & & 17 & 56.67 \\
& $31-40$ & & 5 & 16.66 \\
& $40-50$ & Jumlah & $\mathbf{3 0}$ & $\mathbf{1 0 0}$ \\
\hline
\end{tabular}

Sumber: Data Olahan (2020)

Berdasarkan hasil rekapitulasi data identitas responden pada tabel diatas dapat dilihat bahwa berdasarkan jenis kelamin laki-laki berjumlah 11 orang dan karyawan perempuan berjumlah 19 orang. Kemudian responden yang berusia 20-30 berjumlah 8 orang sedangkan rentang usia 31-40 berjumlah 17 orang. Dan rentang usia 41-50 hanya berjumlah 5 orang.

\section{Uji Validitas}

Menurut Duwi (2014) uji validitas item merupakan uji instrumen data untuk mengetahui seberapa cermat suatu item dalam mengukur apa yang ingin diukur. Item dapat dikatakan valid jika adanya korelasi yang signifikan dengan skor totalnya, hal ini menunjukkan adanya dukungan item tersebut dalam mengungkap suatu yang ingin diungkap. Item biasanya berupa pertanyaan atau 
pernyataan yang ditujukan kepada kuesioner dengan tujuan untuk responden dengan menggunakan bentuk mengungkapkan sesuatu.

Tabel 3. Hasil Uji Validitas Motivasi

\begin{tabular}{ccc}
\hline No. Soal & Nilai Signifikan & Keterangan \\
\hline 1 & 0.000 & Valid \\
\hline 2 & 0.000 & Valid \\
\hline 3 & 0.000 & Valid \\
\hline 4 & 0.000 & Valid \\
\hline 5 & 0.000 & Valid \\
\hline 6 & 0.000 & Valid \\
\hline 7 & 0.010 & Valid \\
\hline 8 & 0.006 & Valid \\
\hline 9 & 0.000 & Valid \\
\hline 10 & 0.000 & Valid
\end{tabular}

Sumber: Data Olahan (2020)

Berdasarkan tabel diatas hasil uji valid dan ini bisa dilanjutkan validitas dinyatakan bahwa variabel penelitiannya.

motivasi yang terdiri dari 10 item Correlations pernyataan dinyatakan bahwa statusnya

Tabel 4. Correlations

\begin{tabular}{|c|c|c|c|c|c|c|c|c|c|c|c|c|}
\hline & & A1 & $\mathrm{A} 2$ & $\mathrm{~A} 3$ & A4 & A5 & A6 & A7 & A8 & A9 & A10 & JUMLAH \\
\hline \multirow[t]{3}{*}{ A1 } & Pearson Correlation & 1 & -.229 & -.229 & -.229 & -.229 & -.229 & -.138 & -.080 & -.229 & -.229 & $-.864^{* *}$ \\
\hline & Sig. (2-tailed) & & .215 & .215 & .215 & .215 & .215 & .458 & .670 & .215 & .215 & .000 \\
\hline & $\mathrm{N}$ & 31 & 31 & 31 & 31 & 31 & 31 & 31 & 31 & 31 & 31 & 31 \\
\hline \multirow[t]{3}{*}{ A2 } & Pearson Correlation & -.229 & 1 & $\begin{array}{l}1.000 \\
* *\end{array}$ & $\begin{array}{l}1.000 \\
* *\end{array}$ & $\begin{array}{l}1.000 \\
* *\end{array}$ & $\begin{array}{l}1.000 \\
* *\end{array}$ & $.632^{* *}$ & $.632^{* *}$ & $1.000^{* *}$ & $1.000^{* *}$ & $.654^{* *}$ \\
\hline & Sig. (2-tailed) & .215 & & .000 & .000 & .000 & .000 & .000 & .000 & .000 & .000 & .000 \\
\hline & $\mathrm{N}$ & 31 & 31 & 31 & 31 & 31 & 31 & 31 & 31 & 31 & 31 & 31 \\
\hline \multirow[t]{3}{*}{ A3 } & Pearson Correlation & -.229 & $\begin{array}{l}1.000 \\
* *\end{array}$ & 1 & $\begin{array}{l}1.000 \\
* *\end{array}$ & $\begin{array}{l}1.000 \\
* *\end{array}$ & $\begin{array}{l}1.000 \\
* *\end{array}$ & $.632^{* *}$ & $.632^{* *}$ & $1.000^{* *}$ & $1.000^{* *}$ & $.654^{* *}$ \\
\hline & Sig. (2-tailed) & .215 & .000 & & .000 & .000 & .000 & .000 & .000 & .000 & .000 & .000 \\
\hline & $\mathrm{N}$ & 31 & 31 & 31 & 31 & 31 & 31 & 31 & 31 & 31 & 31 & 31 \\
\hline \multirow[t]{3}{*}{ A4 } & Pearson Correlation & -.229 & $\begin{array}{l}1.000 \\
* *\end{array}$ & $\begin{array}{l}1.000 \\
* *\end{array}$ & 1 & $\begin{array}{l}1.000 \\
* *\end{array}$ & $\begin{array}{l}1.000 \\
* *\end{array}$ & $.632^{* *}$ & $.632^{* *}$ & $1.000^{* *}$ & $1.000^{* *}$ & $.654^{* *}$ \\
\hline & Sig. (2-tailed) & .215 & .000 & .000 & & .000 & .000 & .000 & .000 & .000 & .000 & .000 \\
\hline & $\mathrm{N}$ & 31 & 31 & 31 & 31 & 31 & 31 & 31 & 31 & 31 & 31 & 31 \\
\hline \multirow[t]{3}{*}{ A5 } & Pearson Correlation & -.229 & $\begin{array}{l}1.000 \\
* *\end{array}$ & $\begin{array}{l}1.000 \\
* *\end{array}$ & $\begin{array}{l}1.000 \\
* *\end{array}$ & 1 & $\begin{array}{l}1.000 \\
* *\end{array}$ & $.632^{* *}$ & $.632^{* *}$ & $1.000^{* *}$ & $1.000^{* *}$ & $.654^{* *}$ \\
\hline & Sig. (2-tailed) & .215 & .000 & .000 & .000 & & .000 & .000 & .000 & .000 & .000 & .000 \\
\hline & $\mathrm{N}$ & 31 & 31 & 31 & 31 & 31 & 31 & 31 & 31 & 31 & 31 & 31 \\
\hline \multirow[t]{3}{*}{ A6 } & Pearson Correlation & -.229 & $\begin{array}{l}1.000 \\
\text { *** }\end{array}$ & $\begin{array}{l}1.000 \\
* *\end{array}$ & $\begin{array}{l}1.000 \\
* *\end{array}$ & $\begin{array}{l}1.000 \\
* *\end{array}$ & 1 & $.632^{* *}$ & $.632^{* *}$ & $1.000^{* *}$ & $1.000^{* *}$ & $.654^{* *}$ \\
\hline & Sig. (2-tailed) & .215 & .000 & .000 & .000 & .000 & & .000 & .000 & .000 & .000 & .000 \\
\hline & $\mathrm{N}$ & 31 & 31 & 31 & 31 & 31 & 31 & 31 & 31 & 31 & 31 & 31 \\
\hline
\end{tabular}




\begin{tabular}{|c|c|c|c|c|c|c|c|c|c|c|c|c|}
\hline \multirow[t]{3}{*}{ A7 } & Pearson Correlation & -.138 & $.632^{* *}$ & $.632^{* *}$ & $.632^{* *}$ & $.632^{* *}$ & $.632^{* *}$ & 1 & $.456^{* *}$ & $.632^{* *}$ & $.632^{* *}$ & $.455^{*}$ \\
\hline & Sig. (2-tailed) & .458 & .000 & .000 & .000 & .000 & .000 & & .010 & .000 & .000 & .010 \\
\hline & $\mathrm{N}$ & 31 & 31 & 31 & 31 & 31 & 31 & 31 & 31 & 31 & 31 & 31 \\
\hline \multirow[t]{3}{*}{ A8 } & Pearson Correlation & -.080 & $.632^{* *}$ & $.632^{* *}$ & $.632^{* *}$ & $.632^{* *}$ & $.632^{* *}$ & $.456^{* *}$ & 1 & $.632^{* *}$ & $.632^{* *}$ & $.486^{* *}$ \\
\hline & Sig. (2-tailed) & .670 & .000 & .000 & .000 & .000 & .000 & .010 & & .000 & .000 & .006 \\
\hline & $\mathrm{N}$ & 31 & 31 & 31 & 31 & 31 & 31 & 31 & 31 & 31 & 31 & 31 \\
\hline \multirow[t]{3}{*}{ A9 } & Pearson Correlation & -.229 & $\begin{array}{l}1.000 \\
* *\end{array}$ & $\begin{array}{l}1.000 \\
* *\end{array}$ & $\begin{array}{l}1.000 \\
* *\end{array}$ & $\begin{array}{l}1.000 \\
* *\end{array}$ & $\begin{array}{l}1.000 \\
* *\end{array}$ & $.632^{* *}$ & $.632^{* *}$ & 1 & $1.000^{* *}$ & $.654^{* *}$ \\
\hline & Sig. (2-tailed) & .215 & .000 & .000 & .000 & .000 & .000 & .000 & .000 & & .000 & .000 \\
\hline & $\mathrm{N}$ & 31 & 31 & 31 & 31 & 31 & 31 & 31 & 31 & 31 & 31 & 31 \\
\hline \multirow[t]{3}{*}{ A10 } & Pearson Correlation & -.229 & $\begin{array}{l}1.000 \\
* *\end{array}$ & $\begin{array}{l}1.000 \\
* *\end{array}$ & $\begin{array}{l}1.000 \\
* *\end{array}$ & $\begin{array}{l}1.000 \\
* *\end{array}$ & $\begin{array}{l}1.000 \\
* *\end{array}$ & $.632^{* *}$ & $.632^{* *}$ & $1.000^{* *}$ & 1 & $.654^{* *}$ \\
\hline & Sig. (2-tailed) & .215 & .000 & .000 & .000 & .000 & .000 & .000 & .000 & .000 & & .000 \\
\hline & $\mathrm{N}$ & 31 & 31 & 31 & 31 & 31 & 31 & 31 & 31 & 31 & 31 & 31 \\
\hline \multirow[t]{3}{*}{$\begin{array}{l}\text { JUM } \\
\text { LAH }\end{array}$} & Pearson Correlation & $.864^{* *}$ & $.654^{* *}$ & $.654^{* *}$ & $.654^{* *}$ & $.654^{* *}$ & $.654^{* *}$ & $.455^{*}$ & $.486^{* *}$ & $.654^{* *}$ & $.654^{* *}$ & 1 \\
\hline & Sig. (2-tailed) & .000 & .000 & .000 & .000 & .000 & .000 & .010 & .006 & .000 & .000 & \\
\hline & $\mathrm{N}$ & 31 & 31 & 31 & 31 & 31 & 31 & 31 & 31 & 31 & 31 & 31 \\
\hline
\end{tabular}

\section{Sumber: Data Olahan (2020)}

Hasil menunjukkan butir butir total signifikasi dari output $<0,05$ maka angket dalam penelitian ini adalah valid. item valid.

Terlihat dalam tabel bahwa dalam skor

Tabel 5. Hasil Uji Validitas Item Etos Kerja

\begin{tabular}{ccc}
\hline No. Soal & Nilai Signifikansi & Keterangan \\
\hline 1 & 0.033 & Valid \\
\hline 2 & 0.000 & Valid \\
\hline 3 & 0.000 & Valid \\
\hline 4 & 0.000 & Valid \\
\hline 5 & 0.000 & Valid \\
\hline 6 & 0.000 & Valid \\
\hline 7 & 0.000 & Valid \\
\hline 8 & 0.000 & Valid \\
\hline 9 & 0.000 & Valid \\
\hline 10 & 0.000 & Valid \\
\hline 11 & 0.000 & Valid \\
\hline 12 & 0.000 & Valid \\
\hline 13 & 0.032 & Valid \\
\hline 14 & 0.000 & Valid \\
\hline 15 & 0.000 & Valid \\
\hline 16 & 0.000 & Valid \\
\hline 17 & 0.000 & Valid \\
\hline 18 & 0.000 & Valid \\
\hline 19 & 0.000 & Valid \\
\hline 20 & 0.000 & Valid \\
\hline 21 & 0.000 & Valid \\
\hline
\end{tabular}




\begin{tabular}{lll}
\hline 22 & 0.032 & Valid \\
\hline 23 & 0.000 & Valid \\
\hline 24 & 0.000 & Valid \\
\hline 25 & 0.000 & Valid \\
\hline 26 & 0.000 & Valid \\
\hline 27 & 0.002 & Valid \\
\hline 28 & 0.000 & Valid \\
\hline 29 & 0.000 & Valid \\
\hline 30 & 0.000 & Valid \\
\hline 31 & 0.032 & Valid \\
\hline 32 & 0.000 & Valid \\
\hline 33 & 0.000 & Valid \\
\hline 34 & 0.000 & Valid \\
\hline 35 & 0.000 & Valid \\
\hline 36 & 0.002 & Valid \\
\hline 37 & 0.000 & Valid \\
\hline 38 & 0.002 & Valid \\
\hline 39 & 0.000 & Valid \\
\hline 40 & 0.000 & Valid
\end{tabular}

\section{Uji Reliabilitas}

Uji Reliabilitas dilakukan untuk mengetahui sejauh mana hasil pengukuran tetap konsisten apabila dilakukan pengukuran dua kali atau lebih terhadap obyek yang sama dengan alat ukur yang sama. Selanjutnya untuk mengetahui reliabilitas dari pernyataan pernyataan dalam angket, digunakan teknik Cronbach's Alpha. Suatu instrumen dianggap reliable, apabila koefisien alpha diatas 0,6. Perhitungan uji reliabilitas dilakukan dengan program statistik.

Tabel 6. Hasil Uji Reliabilitas

Reliability Statistics

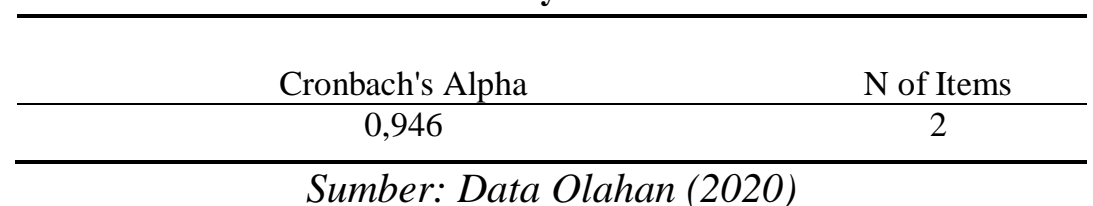

Hasil uji reliabilitas diatas menunujukkan secara keseluruhan variabel diperoleh nilai Cronbach's Alpha sebesar 0,946 atau lebih besar dari 0,6 sehingga dapat disimpulkan bahwa seluruh item pernyataan dalam penelitian ini memenuhi syarat reliabilitas atau dengan kata lain bahwa angket ini reliable sebagai instrumen penelitian.

\section{Uji Normalitas}

Pengujian normalitas digunakan untuk mengujji apakah data dari sampel yang diambil normal atau tidak. Metode yang digunakan dalam penelitian ini adalah uji Kolmogrov-Smirnov, dengan pengujiannya apabila nilai Asymp.Sig diatas 0,05 maka data tidak berdistribusi normal. Adapun berdasarkan hasil analisis normalitas diperoleh sebagai berikut : 
Tabel 7. Hasil Analisis Normalitas

One-Sample Kolmogorov-Smirnov Test

\begin{tabular}{llrr}
\hline & & MOTIVASI & ETOS \\
\hline $\mathrm{N}$ & & 30 & 30 \\
\hline Normal Parameters $^{\text {a,b }}$ & Mean & 45,8667 & 180,5333 \\
\cline { 2 - 4 } & Std. Deviation & 4,15836 & 13,43627 \\
\hline Most Extreme & Absolute & 0,246 & 0,160 \\
\cline { 2 - 4 } Differences & Positive & 0,246 & 0,160 \\
\cline { 2 - 4 } & Negative & -0.241 & -0.151 \\
\hline Test Statistic & & 0,546 & 0,660 \\
\hline Asymp. Sig. (2-tailed) & & $.912^{0}$ & $.747^{0}$ \\
\hline a. Test distribution is Normal & & \\
b. Calculated from data & & &
\end{tabular}

Sumber: Data Olahan (2020)

Hasil uji normalitas menunjukkan Asymp.Sig Kolmogorov-Smirnov pada variable motivasi sebesar 0,912 dan etos sebesar 0,747. Dari hasil tersebut menunjukkan nilai signifikansi atau probanilitas lebih besar dari taraf signifikan 0,05 yang berarti variabel terdistribusi normal.

\section{Uji T}

Berdasarkan hasil pengujian dengan menggunakan SPSS diperoleh ringkasan hasil sebagai berikut:

Tabel 8. Hasil Analisis Uji T

\begin{tabular}{|c|c|c|c|c|c|c|}
\hline & \multicolumn{6}{|c|}{ Test Value $=\mathbf{0}$} \\
\hline & \multirow[t]{2}{*}{$\mathrm{t}$} & \multirow[t]{2}{*}{ df } & \multirow{2}{*}{$\begin{array}{l}\text { Sig (2- } \\
\text { tailed) }\end{array}$} & \multirow{2}{*}{$\begin{array}{c}\text { Mean } \\
\text { Difference }\end{array}$} & \multicolumn{2}{|c|}{$95 \%$ confidence } \\
\hline & & & & & Lower & Upper \\
\hline Motivasi & 60,414 & 29 & 0,000 & 45,86667 & 44,3139 & 47,4194 \\
\hline Etos & 73593 & 29 & 0,000 & 180,53333 & 175,5161 & 185,5505 \\
\hline
\end{tabular}

Sumber: Data Olahan (2020)

Menggunakan taraf signifikan $(\alpha)$ $=0,05$ diperoleh $\mathrm{T}$ Tabel -2,045, dengan kriteria pengujian Ho diterima apabila $\mathrm{T}$ Hitung < -2,045 dan Ho ditolak apabila $\mathrm{T}$ Hitung > -2,045. Berdasarkan pengujian maka dapat diketahui bahwa $\mathrm{T}$ hitung $(60,414)$ lebih besar dari $\mathrm{T}$ table $(-2,045)$ sehingga Ho ditolak dan Ha diterima dan bila dilihat berdasarkan signigikansi 0,000 $<0,005$ maka Ho di tolak Ha di terima yang berarti terdapat pengaruh yang signifikan dari variabel motivasi terhadap etos kerja Islami.
Dari Hasil Penelitian dan uji yang ada di atas maka dapat kita ketahui bahwa motivasi yang ada di Universitas Muhammadiyah Riau terdapat pengaruh yang signifikan terhadap Etos Kerja Islami yang dijalankan saat ini, mengingat UMRI merupakan salah satu Universitas Swasta di bawah naungan Muhammadiyah yang tentunya memiliki standar kinerja Karyawan berdasarkan Al Islam dan Kemuhammadiyahan. Setiap semester UMRI melakukan monitoring evaluasi kinerja dosen dan karyawan 
berdasarkan atas SPMI yang telah dijalankan, dan hal ini terus dilakukan demi tercapainya satu siklus penjaminan Mutu PPEPP (Penetapan, Pelaksanaan, Evaluasi Pengendalian dan Peningkatan) hal ini tentunya dapat menunjang jenjang karir karyawan UMRI.

Mengenai Jaminan Kerja karyawan, UMRI memiliki aturan baku yang telah dijalankan seperti, Jaminan Kesehatan (BPJS Kesehatan) dilengkapi oleh Klinik Pratama UMRI, Jaminan Hari Tua (BPJS Ketenagakerjaan) yang kesemuanya ini menjadikan karyawan UMRI merasa nyaman dan aman bekerja dilingkungan UMRI. UMRI terletak di pusat kota Pekanbaru yang berada pada perempatan emas diapit oleh beberapa mall dan beberapa hotel manjadikan tata letak UMRI menjadi salah satu Universitas yang strategis dan bernilai jual tinggi, dengan keberadaan ini UMRI menjadi salah satu Universitas yang dapat dijangkau dengan berbagai macam moda transportasi saat ini dan menjadi salah satu universitas swasta yang diperhitungkan di Provisi Riau. Universitas Muhammadiyah Riau mempunyai lembaga Kontrol mutu yang dinamakan dengan lembaga LP2KM (Lembaga Pengembangan Pendidikan dan Kontrol Mutu) dan aspek aspek motivasi yang telah dimiliki UMRI maka terciptalah etos kerja yang professional serta bertanggung jawab hal ini selaras dengan etos kerja Islami yang ingin diciptakan, perkerjaan bukan hanya sekedar mencari penghasilan tetapi bernilai ibadah sesuai dengan semboyan Muhammadiyah "Hidup hidupilah Muhammadiyah tetapi jangan mencari hidup di Muhammadiyah".

\section{KESIMPULAN}

Dari hasil penelitian terhadap 30 orang sampel responden yang terdiri dari 11 orang laki laki dan 19 orang perempuan dengan rentang usia berusia 20-30 berjumlah 8 orang sedangkan rentang usia 31-40 berjumlah 17 orang. Dan rentang usia 41-50 hanya berjumlah 5 orang Pengaruh Motivasi terhadap Etos Kerja Islami di Universitas Muhammadiyah Riau hasilnya berpengaruh sangat signifikan hal ini dibuktikan dengan beberapa Motivasi yang telah dijalankan dapat menghasilkan karyawan yang memiliki Etos Kerja Islami Yang terukur berdasarkan nilai keislaman diantaranya adalah, kejujuran, bertanggung jawabm disiplin, gigih serta mengharap ridho Allah SWT atas pekerjaan yang dilakukan. Bekerja di Universitas Muhammadiyah Riau bukan hanya sebagai ladang mencari penghasilan tetapi sarana ladang menjalankan ibadah sesuai dengan semboyan Muhammadiyah "Hidup hidupilah Muhammadiyah tetapi jangan mencari hidup di Muhammadiyah".

\section{DAFTAR PUSTAKA}

Bhargava R. Kotur \& S. Anbazhagan. 2014. Education and Work Experience-Influence on the Performance. IOSR Journal of Business and Management (IOSRJBM), 16(5), 104-110.

Duwi, Priyatno. 2014. SPSS 22 : Pengolahan Data Terpraktis. CV. Andi Offset. Yogyakarta

Hamzah. 2008. Teori Motivasi dan Pengukuranya. Bumi Aksara. Jakarta.

Hasibuan, Malayu. 2002. Perilaku Manajemen Organisasi. Bumi Aksara. Jakarta.

Lubis, Yusniar., Hermanto, Bambang., \& Edison, Emron. 2018. Manajemen dan Riset Sumber Daya Manusia. Alfabeta, CV. Bandung.

Musriha. 2011. Influences of Work Behavior, Work Environment and Motivation in Clove Cigarette Factories in Kudus, Indonesia. 
Journal Of Academic Research International, 1(3), 303-314.

Nitisusastro, Mulyadi. 2012. Perilaku Konsumen dalam Perspektif Kewirausahaan. Alfabeta. Bandung.

Samsudin, Sadili. 2010. Manajemen Sumber Daya Manusia. Pustaka Setia. Jakarta.

Schiffman, Leon G \& Kanuk, Leslie Lazar. 2008. Perilaku Konsumen. PT. Indeks. Jakarta.

Sedarmayanti, 2009. Sumber Daya Manusia dan Produktivitas Kerja. Mandar Maju. Bandung

Siagian, Sondang. 2004. Manajemen Sumber Daya Manusia. Bumi Aksara. Jakarta.

Sugiyono. 2016. Metode Penelitian Kuantitatif, Kualitatif dan $R \& D$. PT Alfabet. Bandung.

Sunyoto, Danang. 2013. Perilaku Konsumen, CAPS (Center Of Academy Publishing Service). Yogyakarta.

Suprapti, Ni Wayan Sri. 2010. Perilaku Konsumen (Pemahaman Dasar dan Aplikasinya dalam Strategi Pemasaran). Udayana University Press. Denpasar.

Usman, Abdul Halim. 2015. Manajemen Strategis Syariah. Zikrul Hakim. Jakarta.

Wibowo. 2011. Manajemen Kinerja. Raja Grafindo Persada. Jakarta. 